\title{
A una flor nacida en una calavera: En torno al concepto de propagación contextual
}

\author{
David Mañero Lozano ${ }^{1}$ (D)
}

Accepted: 25 August 2021 / Published online: 25 October 2021

(c) The Author(s) 2021

\begin{abstract}
This study deals with the way in which the literary motif of the flower born in a skull was transmitted. In particular, it is analyzed the textual formulation that emerged in baroque poetry and how it was projected later in several cultural contexts. In addition, this analysis tries to illustrate the concept of contextual propagation, which refers to a process of literary transmission that explains the survival and evolution of certain texts through new channels of expression involving a change in literary genre and even expressive medium.
\end{abstract}

Keywords Oral literature $\cdot$ Traditional poetry $\cdot$ Legends $\cdot$ Folk tales $\cdot$ Internet Graffiti

\section{Variantes de un motivo universal y delimitación de objetivos}

La imagen de la planta que germina de los restos mortales, con variantes como las flores que nacen de la sangre o de las lágrimas vertidas por la muerte de la persona amada, es un tópico recreado en tradiciones tan diversas como la mitología egipcia y la griega, las leyendas alemanas o los cuentos de la Bretaña. ${ }^{1}$ Baste recordar como ejemplo, dentro del ámbito hispánico, la metamorfosis triunfal del amor en el conocido desenlace del romance del Conde Niño, expresada así en esta versión oral registrada en Los pozuelos de Calatrava (Ciudad Real):

A ella, como hija de reyes, la entierran en el altar, a él, como hijo de conde, unos pasos más atrás.

De ella nace un rosal blanco, de él, un espino fugaz;

las ramitas que se alcanzan fuertes abrazos se dan. (CLO, 857r)

\footnotetext{
${ }^{1}$ A propósito de la sangre y de las lágrimas, remito a los ejemplos anotados por Saintyves (1985: 39, n. $30)$.

David Mañero Lozano

dmanero@ujaen.es

1 Universidad de Jaén, Jaén, Spain
} 
Idéntico motivo (E631.0.1 del índice de Thompson, 1966) nos encontramos en el final de la balada de Bárbara Allen, una de las más difundidas de la tradición inglesa. Traduzco una muestra ofrecida por Gary H. Gossen, aprendida de su abuelo David Marsh Hamilton hacia 1955:

They buried her in the high church yard, | they buried him close by her, out of his bosom there grew a red rose, | out of her backbone a briar. They grew and they grew | on the old church tower, | til they could grow no higher, | | and there they tied in a true love's knot $\mid$ for all true loves to admire. (Gutiérrez Estévez: 2019, 8).

La enterraron en el patio de la iglesia alta, | lo enterraron cerca de ella, || de su pecho creció una rosa roja, | de su columna un rosal silvestre. || Crecieron y crecieron | en la vieja torre de la iglesia, | hasta que no pudieron crecer más, | y allí se unieron en un auténtico nudo de amor | para ser admirados entre todos los amores verdaderos.

La capacidad de propagación del motivo a otros romances, quizá por influencia de Conde Niño, puede apreciarse en esta extraña versión de Agustinita y Redondo documentada en 2004 en Alcolea (Córdoba, España):

Lo llevaron a enterrar, lo paran en medio el nicho;

salió una voz que decía: ——Ya está aquí to mi cariño——.

En mitad de los dos nichos, ha nacido un gran rosal,

y eran los dos amorcitos, que estaban gozando ya. (CLO, 1258r)

Los paralelos son también apreciables en otros relatos más lejanos, como los transmitidos por los beduinos del desierto de Libia (Argenter i Giralt, 2015) y las leyendas mexicanas de la princesa zapoteca Donají y de la creación del pulque, a las que más adelante haré referencia. ${ }^{2}$

Es, sin embargo, en la poesía barroca española, hacia la segunda mitad del s. XVII, cuando este tópico adquiere la configuración que me interesa analizar en estas páginas, consistente en la representación de una flor nacida en una calavera. ${ }^{3} \mathrm{La}$ imagen cuenta con antecedentes en el género de la emblemática, ${ }^{4}$ si bien se relacionan con una tradición textual que se aparta, según veremos, de los objetivos del presente estudio. Remito tan solo, a manera de muestra, a una figura de los emblemas latinos de Boissard (1588: sign. E4r), en la que se representa una mata de trigo nacida junto a unos huesos y una calavera como símbolo cristiano de la resurrección del alma:

\footnotetext{
2 Agradezco a Grissel Gómez Estrada que me diese noticia de estas leyendas. La primera de ellas narra cómo un pastor descubrió el lugar donde se había enterrado la cabeza de la princesa Donají, separada del cuerpo, al intentar arrancar de raíz una azucena que había nacido dentro de la oreja de esta mujer. En cuanto a la leyenda de la creación del pulque, se cuenta que, de los huesos de Mayahuel, enterrados por Quetzalcóatl, nació el maguey, de cuyo tronco se extrae el líquido con el que se elabora el pulque. Quisiera apuntar también la posible asociación de las leyendas de Donají y Mayahuel con el cuento internacional ATU 780 (The Singing Bone) y con leyendas folclóricas y literarias de amplios alcances. Véase al respecto Cristóbal (1999) y Garrosa Gude (2010).

${ }^{3}$ Sobre el motivo de la botanical bosom serpent, es decir, las plantas que nacen del interior o de la piel de los cuerpos, véase Ermacora (2020).

${ }^{4}$ Agradezco a Sagrario López Poza que me diera noticia de este emblema.
} 


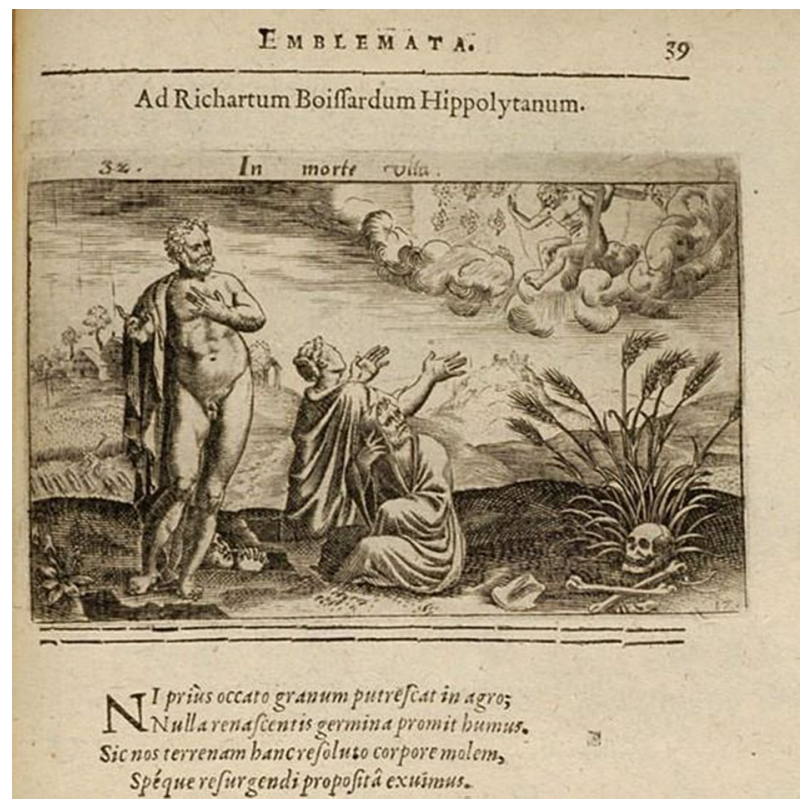

(URL: www.emblems.arts.gla.ac.uk/french/emblem.php?id=FBOa015).

No me propongo, con todo, rastrear el tratamiento histórico de esta imagen, de la que encontramos reelaboraciones dentro del género de la emblemática. ${ }^{5}$ Mi objetivo prioritario será indagar específicamente sobre las motivaciones que permitieron la pervivencia del tópico en diversos contextos a lo largo de más de tres siglos, hasta llegar, como veremos, al momento actual. A partir de este análisis, desarrollaré el concepto de propagación contextual, con el que me refiero a un proceso de transmisión literaria que, en mi opinión, explica la pervivencia de determinados textos a través de nuevos cauces de expresión.

\section{Contextos de transmisión. De la difusión textual a la tradición oral, internáutica y grafitera}

En 1680, Francisco Mestre, quien ostenta el título de impresor del Santo Tribunal de la Inquisición, estampó en Valencia, con muy buen sentido comercial, ${ }^{6}$ una de las últimas compilaciones de la lírica áurea, titulada Varias hermosas flores del Parnaso... Juan Bautista Aguilar, responsable de la selección de poemas, incluyó varias

\footnotetext{
5 Remito a los testimonios aportados en Montiel López (2006: 38), donde se reproduce el emblema "Mors vitae initium" recogido en George Wither, A collection of emblemes, ancient and moderne, 1635.

6 Para una visión panorámica de la mercadotecnia de los denominados "Parnasos", remito a Infantes (2007).
} 
composiciones relacionadas con el tópico que nos ocupa. La primera de ellas consta de cuatro décimas atribuidas a Antonio de Solís, tituladas "A una azucena que nació junto a una calavera" (sign. M3r-v). El poema presenta la imagen de una flor que brota cerca de un cráneo, lo que da pie a exponer una serie de contrastes entre la risa y el llanto, el nacimiento y la muerte, etc., con el evidente propósito de disuadir del "loco devaneo" y la vanidad "a la vista del escarmiento", y en definitiva se aconseja la castidad, palabra clave con la que se cierra el texto.

A continuación, se añade un poema atribuido a Francisco de la Torre y Sevil dedicado "al mismo asunto" (sign. M3v-N1r), en el que, a lo largo de ocho décimas, se desarrollan los mismos tópicos moralizantes. ${ }^{7}$ En particular, conviene destacar la última estrofa, que, independizada del resto de la composición, tendrá especial fortuna en la tradición poética venidera:

Oh, flor bella y desdichada

junto a fealdad espantosa,

que cuanto tienes de hermosa,

has de vivir de asustada.

¿Dónde irás, fija o cortada,

que escapes de infausta suerte?

Que arrancarte es golpe fuerte;

dejarte, muerte crecida,

pues dejarte con la vida

es dejarte con la muerte.

Tanto este poema atribuido a Francisco de la Torre y Sevil como el de Antonio Solís fueron transcritos y comentados ochenta años más tarde por Francisco Mariano Nifo en una aparatosa miscelánea repleta de moralizaciones, el Cajón de sastre, o montón de muchas cosas buenas, mejores y medianas, impreso en Madrid en 1761 y de nuevo en 1781. En concreto, dentro de su "Número tercero" de la edición príncipe, dedicado a "La mujer considerada como agente auxiliar de la felicidad del hombre", se recogen íntegramente ambas composiciones, a lo que sigue un vacuo comentario sobre los supuestos efectos perniciosos de la belleza femenina (sign. H1v-H2r). Queda por tanto de manifiesto el componente de adoctrinamiento moral que propició la difusión del poema en las mencionadas impresiones, cuestión que convendrá tratar más adelante. En cualquier caso, lo que me interesa resaltar ahora es cómo, casi un siglo después de su publicación, escritores como Nifo aún tienen en alta consideración el "divino volumen" (sign. K2r) preparado por Juan Bautista Aguilar, lo que contribuye a trazar el mapa de su recepción literaria, y en concreto de los dos poemas que nos ocupan. Por lo demás, la memoria de estos poemas aún

\footnotetext{
7 Esta composición se recoge también en el volumen facticio titulado Papeles curiosos manuscritos (MSS/10924 de la BNE): Décimas que sacó Don Francisco de la Torre y Sevil, a una azucena, que nació junto a una calavera (h. 180v-183v). Contamos con transcripción moderna basada en este manuscrito en Alvar (1987: 253-254). Carreira (2013: 17) señala la proximidad temática con el soneto «A una rosa que nació en una calavera» de Pedro de Quirós.
} 
sigue viva en otras obras que los reproducen, como las Cartas crítico-poéticas publicadas en Sánchez Plazuelos (1862: 152).

Pues bien, la composición se difundió en múltiples áreas del ámbito hispánico mediante cauces diversos. Un primer foco de transmisión fue a través de relatos cada vez más prolijos en detalles que, según comprobaremos, pertenecen al género de lo legendario. En los más variados contextos culturales, observamos cómo los versos originalmente asociados a Francisco de la Torre y Sevil se atribuyen a diferentes poetas o intelectuales en un acto de creación espontánea. De este modo, la autoría del poema recae sobre el chileno Manuel José de Oteiza y Dongo (1742-1798), quien, según asegura Valderrama (1866: 184), compuso esta "décima de circunstancias [que] fue hecha en el cementerio, a una flor que había nacido por casualidad sobre un poco de tierra adherido a un cráneo". 8

Este relato legendario tuvo un fuerte arraigo en Hispanoamérica, pues la siguiente muestra de la que tengo constancia se documenta catorce años después en Colombia, donde el poeta José Joaquín Ortiz, a propósito de uno de los poemas incluidos en la edición de sus obras, al que titula $A$ una rosa nacida en una calavera (Ortiz Rojas, 1880: 212-213), añade esta nota explicativa:

Don Francisco de Quevedo improvisó, según cuentan, los versos siguientes, al ver que había nacido una rosa en una calavera:

Bella flor, cuando naciste, ¡qué funesta fue tu suerte!

Al primer paso que diste,

tropezaste con la muerte.

Dejarte aquí es cosa triste,

y llevarte es cosa fuerte;

dejarte donde naciste

es dejarte con la muerte. ${ }^{9}$

Mi poesía no es sino amplificación del pensamiento del insigne poeta español.

(Ortiz Rojas, 1880: 237)

He citado estos versos, que en parte coinciden con los ya leídos del impreso de las Varias hermosas flores del parnaso de 1680, porque estamos ante una versión diferente en la que se adopta la forma de cuarteta doble en lugar de la décima. Salta a la vista, por otro lado, la proximidad de la segunda cuarteta con los versos finales de la décima atribuida a Francisco de la Torre y Sevil. En cuanto a la primera cuarteta, según he observado, existe un paralelismo muy cercano de sus dos últimos versos con el final de la primera de las cuatro décimas antes mencionadas de Antonio de Solís, donde leemos: "Al primer paso de vida / encontraste con la muerte" (sign. M3r).

\footnotetext{
${ }^{8}$ Remito asimismo a Vela (1922: 209) y Albareda y Garfias (1961: 18-19 y 101), que reproducen la misma información y la transcripción del texto.

${ }^{9}$ Esta versión del texto se reproduce sin variantes en la edición del 30 de septiembre de 1882 del periódico madrileño La ilustración española y americana (año 26, n. ${ }^{\circ} 36$, p. 187), al comienzo de la sección "Trilogía", a lo que sigue el poema de José Joaquín Ortiz y otro del también colombiano Rafael Pombo.
} 
Se trata, según creo, de una reelaboración popular de ambos poemas que, como se verá más adelante, tuvo una extraordinaria difusión en la tradición oral de todo el ámbito hispánico. ${ }^{10}$ De hecho, esta versión en forma de cuarteta doble fue la que con mayor frecuencia se atribuyó, con variantes que delatan su procedencia oral, a distintos escritores que protagonizan las narraciones legendarias.

La atribución a Quevedo, asumida por otros muchos autores, ${ }^{11}$ no es la única que encontramos en la tradición española. Recordemos también la edición preparada en 1902 por Emilio Vicedo de la poesía de Francisco Ganga Ager, escritor español apodado "El Seráfico", quien fue conocido por su fama de improvisador. Según afirma el editor, Ganga recitó espontáneamente el poema que nos ocupa, en este caso la décima, al contemplar una florecilla que asomaba en la cuenca de una calavera en el cementerio de Alicante. $^{12}$

Por su parte, Alberto Muñoz Vernaza, diplomático ecuatoriano que dedicó algunos ensayos a la obra del escritor argentino José Antonio Miralla (1791-1825), recoge las siguientes palabras de Juan Francisco Ortiz, ${ }^{13}$ en las que apreciamos un especial detenimiento en los detalles narrativos, a lo que sigue la versión del poema en forma de doble cuarteta:

Cuentan, dice el distinguido literato colombiano Dr. Juan Francisco Ortiz, que habiendo salido de paseo con varios amigos entraron en el cementerio de Bogotá, y uno de ellos reparó que en una calavera abandonada encima de una tumba había brotado una amapola que se mecía con el viento de la tarde, y mostrándosele a Miralla le pidió un verso, y que improvisó este: "Bella flor, cuando naciste,/¡oh, qué triste fue tu suerte! [...]” (Muñoz Venzalá, 1903: 76).

De manera significativa, en la Antología de poetas argentinos de Puig, ${ }^{14}$ después de transcribir este mismo fragmento, se apostilla: "sin embargo, esta octava ha sido

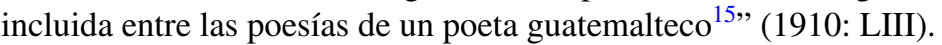

Otro editor, Moreno-Mora, en una antología poética titulada El Azuay literario, incluye la décima como único ejemplo de la poesía del escritor ecuatoriano Ignacio

\footnotetext{
${ }^{10}$ No son infrecuentes las adaptaciones de poemas cultos a las formas empleadas en la poesía de tradición popular. Es el caso, por ejemplo, mencionado por Menéndez Pidal de la redondilla No corras, arroyo, ufano de Antonio de Mendoza, también tradicionalizada, como en el caso que nos ocupa, en forma de copla con rima asonante en los versos pares (apud Alvar, 1959: 22-23).

11 Es el caso de Restrepo (1929: 383). No faltan atribuciones a Quevedo en publicaciones especializadas más recientes, como la de Matos Moctezuma (1980: 30), entre otras. Remito también al erudito y certero estudio de Arrom (1950: 106), donde se alude, entre otros muchos paralelos, a la difusión de la leyenda en Santo Domingo, para lo que remite a Rodríguez Demorizi (1938: 172).

12 La noticia es recogida con escepticismo por Navarro González (1986: 3), quien prefiere relegar la décima al apartado de "versos atribuidos" de su edición.

13 Aunque no he podido localizar la fuente original de la que Muñoz Vernaza copia las palabras de Juan Francisco Ortiz, el cotejo con la segunda edición de las Reminiscencias de d. Juan Francisco Ortiz (1808-1861) evidencia que se trata de una cita literal (Ortiz, 1914: 119-120).

14 Remito asimismo a la obra de Labougle (1924: 50-51), biógrafo de José Antonio Miralla, quien también transcribe casi a la letra la misma cita, a lo que añade: "Años después escritores cubanos discutieron, sin éxito, la paternidad de esas estrofas".

15 Idéntica afirmación encontramos ya en 1865 (Vergara y Vergara, 1931: III, 289).
} 
de Escandón (nacido hacia 1726), y añade al pie la siguiente nota explicativa, sin precisar su fuente de información: "Escandón compuso esta décima al encontrar un rosal florido en una calavera humana" (1930: 8). La noticia será transmitida en términos similares por otros especialistas como Tello, quien se refiere casi un siglo después a esta "afortunada décima inspirada en la contemplación de una planta florecida en la cuenca de una calavera" (2004: 51).

La misma leyenda reaparece asociada a la figura del poeta Miguel Hernández, a quien se atribuyó también la invención del poema, en este caso en su modelo de doble cuarteta con algunas variantes. Quien recogió el testimonio en el que se basa esta nueva atribución, según indica Riquelme, fue un paisano del escritor que anotó los versos recitados por este hacia 1932:

Hernández, al contemplar una flor que retoñaba sobre el hueco ocular de una calavera en el cementerio de Orihuela, fue requerido para versificarcomo lo hiciera con la famosa décima a Álvaro Botella, a imitación de la composición del soneto quevedesco—_, y exclamó: “¡Pobre flor! ¡Qué mal naciste! [(etc.)]" (1986: 108). ${ }^{16}$

El paisano en cuestión, llamado Antonio Giménez Ibarra, ratificó la noticia con posterioridad, hacia 2009, en una entrevista concedida a Nuria Illescas, donde recrea con pormenor los detalles, que merece la pena reproducir íntegramente:

Miguel se reunía en la Tahona con sus amigos para recitar poesías, pero no fue allí donde tuve la ocasión de escucharlo sino en el cementerio. Yo iba al cementerio con frecuencia porque se había muerto un primo mío y Miguel que tenía costumbre de ir mucho por allí. Se encontraba un día con unos amigos en la puerta de entrada del cementerio. A los lados, había dos bancos de obra adosados a la pared, donde estábamos sentados. Uno de los que acompañaban a Miguel le dijo: “¿por qué no nos dices alguna poesía de este lugar?”. Enseguida dijo Miguel: "Escuchad: entró una vez un poeta a un viejo cementerio y vio en un rincón un montón de huesos y en una calavera había germinado una florecilla silvestre, de las que nacen en el campo, y dijo: “¡Pobre flor! ¡Qué mal naciste! / ¿Qué fatal que fue tu suerte! [...]”.

Aquello me gustó tanto que le dije a Miguel Hernández que me lo copiara. Llevaba un papel de estraza en el bolsillo de mi pantalón. Lo saqué y me lo puse a copiar. Miguel terminó de copiarlo. Me lo dedicó y lo guardé. Estos versos no los había revelado hasta el cincuenta aniversario de su muerte. Ahora los sigo recordando día tras día, ya que es para mí uno de los poemas más bellos de Miguel (Illescas, 2009-2010: s. p.).

\footnotetext{
${ }^{16}$ En una nota posterior de Riquelme (1990: 318, n. 182), se precisa: "Copiado por Antonio Jiménez de la misma voz del poeta, acompañado por Francisco Ortuño, José Córdoba y «El Arriero», que cantaba en la Tahona de los Fenoll, en una visita al cementerio oriolano".
} 
Dejada a un lado la interpretación dada por Giménez Ibarra, estamos ante un relato dentro del relato, en el que el protagonista de la anécdota recuerda a su vez una de tantas versiones de la leyenda de la flor nacida en la calavera, por lo que no cabe inferir que el propio Miguel Hernández se atribuyese los versos, de los que, según hemos visto, ya se registran versiones desde 1880 .

Detengámonos ahora en un testimonio oral que, en mi opinión, podría tratarse de una variante de esta leyenda, si bien se aprecian circunstancias diferentes que me interesa comentar. Me refiero a un valioso repertorio y estudio de la literatura oral y la cultura popular de Villarta de San Juan (Ciudad Real), en el que Heredia Menchero (2018: 595-ss.) incluye una sección de epitafios. El primero de ellos (etnotexto n. ${ }^{\circ}$ 982, con el título Epitafio sin identificar), no está copiado por el recopilador de una tumba, sino recitado por una informante llamada Josefina Merino. El texto comienza: "Misericordiosísimo Jesús, /dadle el descanso eterno", y a continuación se transcribe la doble cuarteta.

Según me aclaró el propio recopilador, a quien le requerí más datos sobre este testimonio, la informante aprendió la composición de su padre, quien aseguraba haberla leído en un cementerio de Ciudad Real y tenía la costumbre de recitársela a su hija. No tenemos garantías de que existiese el epitafio en cuestión, pero lo cierto es que, en el transcurso de los años, el padre de la informante recordó las cuartetas indisociablemente unidas al supuesto contexto de la visita a un cementerio.

En el blog Bimenalia de Luis Miguel Montes Arboleya, cronista oficial de Bimenes (Asturias, España), dentro de la sección "Historias mínimas", se reproduce la versión en doble cuarteta del poema recitada por una informante llamada Luisina la de Rosario, a lo que se acompaña la nota: "se podía leer en el antiguo y desaparecido cementerio de La Pamplina de San Julián (hoy está ocupado por la barriá vieya)" (Montes Arboleya, 2004: s. p.). Al igual que en el anterior caso, tan solo tenemos la certidumbre de que el testimonio se transmitió oralmente y tuvo su presunto origen en un epitafio.

Existe, si atendemos también a los canales de transmisión de narraciones virtuales, un foro de Internet denominado Yahoo! Respuestas en el que, durante los años 2010 a 2014, los usuarios intentaron dar contestación a la pregunta "¿Quién es el autor de esta hermosa poesía y qué significa?", referida precisamente a la versión en doble cuarteta del tema que nos ocupa. La variedad de las respuestas es sorprendente. Entre ellas, encontramos una variante de relatos ya mencionados, como el de Miguel Hernández en su visita a un cementerio. Por su parte, una de las participantes del foro, apodada Luna, atribuye el poema a Lord Byron mediante el siguiente relato:

Lord Byron-poeta inglés y lo exclamó un día cuando visitaba la tumba de su madre y chocó con los restos de un cráneo-calavera en donde en su interior, había nacido una pequeña flor (AA. VV., 2010-2014: s. n.). ${ }^{17}$

En palabras de otro de los internautas, que apela a su experiencia vital:

\footnotetext{
17 En adelante, en la transcripción de testimonios extraídos de los internautas, intervengo sin más aviso en la ortografía.
} 
Según se me enseñó en mis años de adolecente, este poema se le asigna a José de Espronceda. ${ }^{18}$ Se comenta que este tenía la particularidad de improvisar versos ante cualquier situación que saliera un poco de lo común. En cierta oportunidad, en que asistía a un funeral, caminando por los senderos del cementerio junto a un grupo de amigos, uno de ellos se encontró con una flor que emergía de la cuenca del ojo de una calavera. Creyendo que pondría en problemas al poeta, lo desafió a componer un verso sobre el episodio.... y Espronceda declamó: "Banca flor, que mal naciste" [(etc.)] (ibíd.).

Para finalizar, los participantes del foro encadenan sin aportar datos adicionales otras cuatro atribuciones categóricas de autoría que recaen sobre Lope de Vega, Quevedo, Bécquer y el poeta argentino Baldomero Fernández Moreno.

De especial interés son también los testimonios compartidos en una página bonaerense de Facebook denominada El club de los libros perdidos, donde se dedica un hilo de comentarios al poema en su forma de doble cuarteta. ${ }^{19}$ En particular, se transmite un relato referido al poeta cubano Hilarion Cabrizas ${ }^{20}$ y dos a Quevedo, a quien se mencionaba en la página de Yahoo! sin aportar detalles. Reproduzco aquí la segunda de las versiones protagonizadas por Quevedo, que forma parte de una tradición extendidísima de cuentecillos folclóricos:

Va el rey junto a Quevedo, pasan por un cementerio y ve una calavera de la que sale un rosa y el rey dice: “¿Qué ironía la vida y la muerte junta!”..., y Don Francisco de Quevedo y Villegas dice: "Rosa que mal naciste,/que mal ha sido tu suerte/[...] Lo mismo que ha escrito Miguel Hernández. ¡Poco inspirado estaría el amigo! (AA. VV., 2013)

En efecto, en la tradición oral peninsular, al igual que en Hispanoamérica, Brasil y EE.UU., Quevedo asume el protagonismo de narraciones que no entran dentro del género de las leyendas, sino de una rama de cuentos populares en los que el escritor funciona como personaje arquetípico que resuelve la narración mediante un golpe de humor o de ingenio. ${ }^{21}$ Muestra, por otra parte, del arraigo del relato de la flor en

\footnotetext{
18 La misma autoría da por supuesta Olivares Figueroa (1950: 299-300).

19 Véanse también a los testimonios personales recogidos en el blog de García (2012).

20 Transcribo el comentario de Marisela Álvarez: "Esa poesía es del poeta Hilarion Cabrizas. Él iba caminando por un campo y se encontró una cabeza de vaca y por una de las cuencas de los ojos había nacido una bellísima flor. Él escribía mucho sobre la muerte, y dice así: «¡Pobre flor! Qué mal naciste,/ qué fatal fue tu suerte,/al primer paso que diste/tropezaste con la muerte./El dejarte es cosa triste,/cogerte es cosa fuerte,/pues dejarte con la vida/es quedarte con la muerte» Me lo contó personalmente mi suegro que conoció al poeta" (AA. VV., 2018).

21 Remito a Pedrosa (2003), quien analiza la tradición de diversas muestras documentadas por otros críticos, además de aportar nuevos testimonios. Otra versión del cuento en el que Quevedo recita las cuartetas ante la visión de una flor que asoma por la cuenca del ojo de una calavera es la recogida en Jiménez Montalvo (2011: 138-139), que forma parte de un esquema narrativo asimilable al tipo 921D*, denominado "las respuestas ingeniosas", del catálogo universal de Aarne y Thompson (1995), a lo que esta investigadora añade la referencia paralela de Camarena y Chevalier (2003: 285-287), registrada bajo el título "El rey Salomón y los pastores sabios".
} 
la calavera en el repertorio cuentístico, es su difusión a través de narraciones en las que el individuo que recita los versos es un personaje anónimo, como sucede en una versión que recogió Asensio García (2011: n. ${ }^{\circ}$ 88) de un informante gitano, en la que el padre de una familia gitana que se desplaza en un carro improvisa el poema al chocar con la calavera de un burro en la que había nacido una flor blanca.

Testimonios como este desempeñan una función que, pese al carácter sentencioso del poema, se aparta del sentido doctrinal que justificó su difusión en la tradición impresa. En efecto, su interpretación queda constreñida a las convenciones sociales que propician la difusión del relato dentro del contexto de transmisión oral, que en este caso consiste básicamente en un medio de entretenimiento, en el que la enseñanza moral tiene un carácter secundario.

Una circunstancia distinta que, hasta fecha de hoy, ha propiciado la difusión del poema en la tradición oral, es su formulación a manera de adivinanza. En una de las campañas de documentación que me ocupé de coordinar en la Sierra de Segura (Jaén), Lola Leal López, informante con 91 años procedente de Hornos de Segura, recitó la versión en cuartetas del poema, con la función de desafiar al receptor a que averiguase la escena representada, que describió después como "una flor nacida en una calavera" ( $C L O, 0197 \mathrm{c})$.

Con anterioridad a este testimonio, en 1980, Checa Beltrán (CLO, 1640c) había documentado una muestra similar en la localidad de Torredonjimeno (Jaén), que reproduce igualmente la configuración de la doble cuarteta. ${ }^{22}$

La composición también se recoge, en versiones más breves, en algunos repertorios argentinos como en el volumen titulado Adivinanzas cordobesas (1971: 62-63) o en las Adivinanzas rioplatenses (Lehmann-Nitsche, 1911: 318), entre otros. La adivinanza se transmitió asimismo en el folclore venezolano (Olivares Figueroa, 1950: 299-300) y en el mexicano, como se aprecia en el siguiente relato de García Valdez, en el que, al hilo de su crónica sobre la vida en la Congregación Rodríguez, en el estado mexicano de Coahuila, recuerda:

Mucha información sobre el pasado del Pueblo nos fue proporcionada en forma oral por el Sr. Teodoro García, ya fallecido, un Sr. que a pesar de sus noventa años siempre conservó una mente muy sana, limpia y lúcida. Pues siempre recordaba nombres de personas, de lugares y de acontecimientos.

Como un recuerdo a su memoria se incluye aquí una especie de acertijo o enigma que él siempre acostumbraba recordar: "Pobre flor que mal naciste [(etc.)]" (García Valdez, 2002: 59-60).

Por su parte, Atero Burgos (2010: I, n. ${ }^{\circ}$ 207) reproduce una muestra de Campo de Gibraltar en la que se transmite de forma aislada la segunda cuarteta: "El dejarte es cosa triste,/el cortarte es cosa fuerte/y el dejarte con la vida/es dejarte con la muerte". La investigadora clasifica estos versos dentro del apartado que denomina "Penas de amor". Más adelante, en la muestra n. 399 de su repertorio gaditano, Atero Burgos transcribe, también aislada, la primera estrofa, que en este caso

\footnotetext{
22 Remito también a la versión alojada por Juan Gómez en su canal de YouTube "Dichos, retahílas y romances de Cortes de Baza" (https://www.youtube.com/watch?v=sQjG4sAjA88).
} 
clasifica en la sección "De sabiduría popular", en particular en el apartado de canciones "Sentenciosas". Tales testimonios ponen de manifiesto, según creo, cómo el poema logra abrirse distintos caminos en la tradición mediante el hallazgo de nuevos contextos que, asociados a interpretaciones muy diversas, prolongan su memoria, en estos últimos casos adaptándose a la forma de cuarteta aislada, tal vez por tratarse de la más habitual en el género de la poesía sentenciosa y la amorosa de tradición oral.

Un contexto en el que también se ha mantenido viva la memoria del poema es el género de los brindis. Según recuerda Luis Alberto Quevedo Mestanza, internauta peruano que interviene en el hilo de Facebook antes mencionado:

Mi padre, siempre cuando hacia sus brindis, comentaba este excelente poema.

Que Dios lo tenga en su gloria. (AA. VV., 2013-)

La atracción suscitada por estos versos alcanzó tal punto que llegaron incluso a plasmarse en un grafiti de la calle Wenceslao Fernández Flórez, en la ciudad de Alicante (España), del que tenemos constancia gracias al proyecto Escrituras expuestas, que compartió una fotografía en su blog el 11 de enero de 2014.

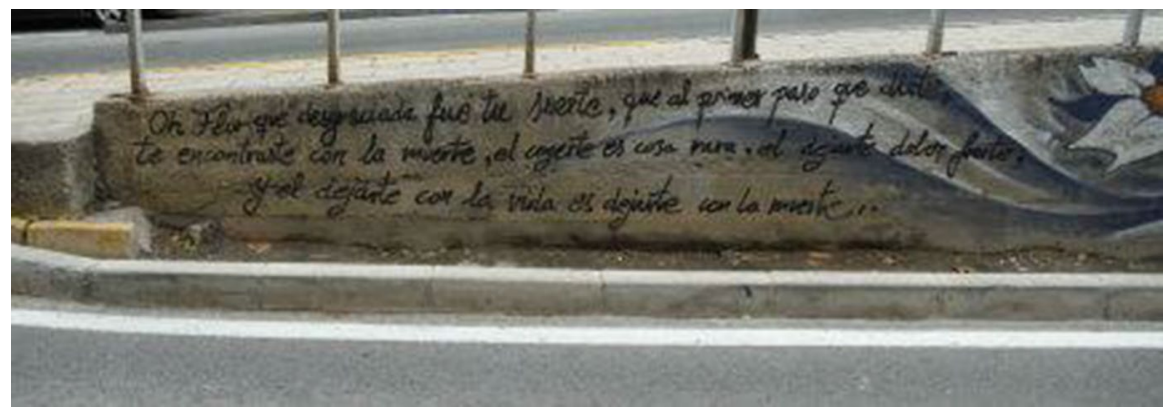

(Ferrer, Mora, Iguarbe et al., 2013-).

Por sorprendente que parezca, la tradición mural de las cuartetas podría remontarse a mediados del siglo XIX. Según afirmó Luis G. Corona, director de la Imprenta del Museo Nacional de México, en la esquina de las calles de San Miguel y Necatitlán de Ciudad de México, existió en 1867 una pulquería llamada "La calavera" en cuya fachada exterior estaba representado un personaje del folclore mexicano, conocido como el Negrito Poeta. Este sostenía en su mano una calavera de la que había nacido una planta en flor, y a un lado de este dibujo figuraban los versos que nos ocupan.

No me parece casual que se pintase precisamente este motivo en el muro de una pulquería. Recordemos que, según una leyenda muy difundida, de los huesos de Mayahuel, enterrados por Quetzalcóatl, nació el maguey, planta de cuyo tronco se extrae el líquido que sirve para la elaboración del pulque. Aún hoy existen pulquerías como Calavera Coyote, local situado en el centro de la ciudad mexicana de 
Puebla que, según puede observarse en su página de Instagram, expone en sus paredes varias representaciones de flores y calaveras.

Esta noticia de la pulquería "La calavera" fue recogida por Nicolás León, como parte de las "rectificaciones y adiciones" que Luis G. Corona le aportó a su libro Agudezas métricas del Negrito Poeta mexicano (apud Matos Moctezuma: 1980: 117). La atribución apócrifa de las cuartetas al Negrito Poeta debió de estar muy extendida en la segunda mitad del s. XIX, a juzgar por una segunda observación transmitida a Nicolás León por el mencionado empleado del Museo Nacional de México. Según advirtió este, en las dos hojas finales de un calendario de 1888, estampado en 1887 por uno de los más célebres editores mexicanos de impresos populares, Antonio Vanegas Arroyo, se escribe lo siguiente:

Para concluir no podemos prescindir de estampar una cuarteta que improvisó en el Panteón de Santa Paula a una flor que nació en la cavidad de un cráneo de los que veíamos allí dispersos, y la que arrancó de la mata: “ßBella flor! ¡Dónde naciste!/¡Qué contraria fue tu suerte!/Que al primer paso que diste,/te encontraste con la muerte" (apud Matos Moctezuma: 1980: 117).

\section{En torno al concepto de "propagación contextual". Una propuesta teórica}

Permítaseme un inciso, antes de exponer las conclusiones, para recordar una teoría inicialmente planteada por el dialectólogo suizo Gilliéron y reformulada medio siglo después en un conocido estudio de Alvar (1958-1959) sobre la poesía tradicional. En palabras de este último, que resumen la hipótesis ensayada en su trabajo, cuando una canción "manifiesta síntomas de agotamiento puede asirse a temas próximos o distantes y salvarse así de la extinción" (22). No es este el lugar para valorar el ejemplo concreto argüido por Alvar, quien intenta demostrar la función "terapéutica" desempeñada por la transformación en romance de una canción nupcial, que de este modo logra perpetuarse en el momento en el que ya casi estaba extinguida. En mi opinión, el proceso desarrollado en este y otros casos similares, en los que una canción abandona el contexto que originalmente le dio vida, debe valorarse desde una perspectiva más amplia, atenta a las circunstancias históricas de su transmisión.

Según creo — - y con esto llego a las conclusiones_—, la adaptación de un determinado tema a un nuevo medio de expresión podría considerarse, si atendemos al proceso de transmisión oral en toda su complejidad, como un fenómeno de migración de contexto o propagación contextual que no en todos los casos implica una transformación del texto ni tampoco el engarce a otros temas de la tradición. ${ }^{23}$

\footnotetext{
${ }^{23}$ Mañero Lozano (2016) desarrolló el concepto de "propagación" literaria para referirse a un recurso compositivo característico de la literatura oral según el cual "determinadas imágenes o metáforas, que tradicionalmente se reservan para la descripción de un elemento en particular, ejercen como «foco propagador» que desencadena la creación de nuevas asociaciones de conceptos cuya comprensión y efecto poético se apoya en la familiaridad del receptor con la imagen originaria" (35). Sin embargo, en este caso no hago referencia a un recurso interno o textual, sino a un tipo de "propagación" de otra índole, que afecta al contexto o circunstancias en las que un texto se transmite.
} 
En efecto, los textos que logran sobrevivir a un determinado contexto cuando este queda desfuncionalizado no siempre cambian de forma ni se injertan en otros temas más vitales, sino que, al margen de estos factores textuales, el principal elemento compartido consiste en el hallazgo de nuevas circunstancias de transmisión que propagan su memoria, sin duda condicionadas por la necesidad de reinterpretar o adaptar el sentido de los textos a nuevos contextos culturales.

El poema sobre la flor nacida en una calavera logró, pues, perdurar hasta el presente gracias a su adaptación o migración a nuevos y tan diversos contextos como los relatos legendarios, los cuentecillos populares, las adivinanzas, las canciones amorosas, los dichos sentenciosos, los brindis, los grafitis y los calendarios. ${ }^{24}$ Una vez más, el estudio de los procesos de transmisión oral nos revela la extraordinaria importancia del contexto, que, según hemos comprobado, debe considerarse como un conjunto de circunstancias de carácter dinámico, con las que los transmisores adaptan su tradición a los avatares de su existencia. Su conocimiento no solo clarifica el sentido de las manifestaciones orales, sino que explica y justifica su existencia misma y su continua evolución.

Funding Open Access funding provided thanks to the CRUE-CSIC agreement with Springer Nature. Este estudio se enmarca dentro del proyecto de I+D de Excelencia del Ministerio de Ciencia, Investigación y Universidades con referencia FFI2017-82344-P), financiado por la Agencia Estatal de Investigación (AEI) y al Fondo Europeo de Desarrollo Regional (FEDER).

Open Access This article is licensed under a Creative Commons Attribution 4.0 International License, which permits use, sharing, adaptation, distribution and reproduction in any medium or format, as long as you give appropriate credit to the original author(s) and the source, provide a link to the Creative Commons licence, and indicate if changes were made. The images or other third party material in this article are included in the article's Creative Commons licence, unless indicated otherwise in a credit line to the material. If material is not included in the article's Creative Commons licence and your intended use is not permitted by statutory regulation or exceeds the permitted use, you will need to obtain permission directly from the copyright holder. To view a copy of this licence, visit http://creativecommons.org/licen ses/by/4.0/.

\section{Referencias}

AA. VV. (2010-2014). ¿Quién es el autor de esta hermosa poesía y qué significa?. Yahoo! Respuestas. https://es.answers.yahoo.com/question/index?qid=20110415142646AA8vwmV\&page=1 $\left[\begin{array}{ll}7 & \mathrm{de}\end{array}\right.$ octubre de 2018]

AA. VV. (2013-). Pobre flor.... El club de los libros perdidos (página de Facebook). https://www.faceb ook.com/elclubdeloslibrosperdidos/posts/pobre-flor-que-mal-naciste-y-que-fatal-fue-tu-suerte-queal-primer-paso-que-dist/601092056619231/ [7 de octubre de 2018]

Aarne, A. y Thompson, S. (1995). Los tipos del cuento folklórico. Una clasificación. Trad. Fernando Peñalosa, Helsinki, Academia Scientiarum Fennica.

Adivinanzas cordobesas (1971). Córdoba (Argentina): Dirección General de Historia, Letras y Ciencias.

\footnotetext{
24 Según estudia Mañero Lozano (2020), La buenaventura del carnaval, canto narrativo de tradición moderna del que se han conservado numerosas versiones, logró tal vez pervivir gracias a su adaptación a contextos de transmisión muy diversos, lo que nos ofrecería otro ejemplo del fenómeno de propagación contextual que aquí nos ocupa.
} 
Albareda, G. \& Garfias, F. (1961). Antología de la poesía hispanoamericana. Madrid, Biblioteca Nueva.

Alvar, Manuel (1987). Edición y estudio del "Entretenimiento de las musas" de don Francisco de la Torre y Sevil. Valencia, Universitat (Honoris Causa, 3).

Alvar, Manuel. (1959). Patología y terapeútica rapsódicas: cómo una canción se convierte en romance. Revista de Filología Española, 42, 19-35.

Argenter i Giralt, Joan A. (2015). Les branques entrellaçades un motiu del folklore verbal i els gèneres mixtos. Estudis de Literatura Oral Popular, 4, 11-32. https://doi.org/10.17345/elop201511-32

Arrom, José Juan (1950). Dos poemas atribuidos a José Antonio Miralla. Estudios de literatura hispanoamericana (93-107). La Habana, Imprenta Ucar, García y Cia.

Asensio García, Javier (2011). Cuentos populares de los gitanos españoles. Madrid, Siruela (Biblioteca de Cuentos Populares, 17).

Atero Burgos, Virtudes (2010). Cancionero gaditano. Cádiz, Universidad de Cádiz.

Boissard, Jean Jacques (1588). Emblemes latins [...] avec l'interpretation Françoise. Metz, Jean Aubry and Abraham Faber. https://www.emblems.arts.gla.ac.uk/french/emblem.php?id=FBOa015

Camarena, J. y Chevalier, M. (2003). Catálogo tipológico del cuento folklórico español. Cuentos-novela, Alcalá de Henares, Centro de Estudios Cervantinos.

Carreira, Antonio (2013). Flores y jardines en la poesía del Siglo de Oro. [Santa María del Cayón, Cantabria], Esles de Cayón (Las Flores del Tilo, 2).

Ermacora, Davide (2020). Plants growing in and on bodies in Folklore. Boletín de Literatura Oral, 10, 109-138. https://doi.org/10.17561/blo.v10.5166

Ferrer, Lidia, Mora, Aitana, Iguarbe, Andrea, Alonso, Juan y Vinader, Irene (2013-). Flor. Escrituras expuestas (blog). https://blogs.ua.es/alicante5/ [7 de octubre de 2018]

Gutiérrez Estévez, Manuel (2019). El incesto y sus símbolos en el romancero oral. Madrid, CSIC (De acá y de allá. Fuentes etnográficas).

García, Rosa (2012-). Poesía inspiradora (blog). https://deblancoavioleta.blogspot.com/2012/05/pobreflor-que-mal-naciste.html [7 de octubre de 2018]

Gómez, Juan (2015). Dichos, retahílas y romances de Cortes de Baza. Canal de YouTube. https://www. youtube.com/watch?v=sQjG4sAjA88 [5 de noviembre de 2018]

Garrosa Gude, José Luis (2010): Lisabetta y el tiesto de albahaca (Decamerón IV, 5): el sustrato folclórico de Boccaccio. Cuadernos de Filología Italiana, volumen extraordinario, 163-177.

García Valdez, Luis (2002). Remembranzas del pasado de Congregación Rodríguez Coahuila antes de 1960. Reseña Histórica de Congregación Rodríguez, Coahuila, Monclova, Coah, Impresora Monclova, 53-62.

Heredia Menchero, José Vicente (2018). Literatura oral y cultura popular de Villarta de San Juan y la Comarca de La Mancha. Roquetas de Mar, Círculo Rojo.

Illescas, Nuria (2009-2010). Testimonio de Antonio Giménez Ibarra sobre Miguel Hernández. El eco hernandiano 2. http://www.elecohernandiano.com/numero_2/index.html

Infantes, Víctor. (2007). «A las poéticas cumbres coronadas»: La orogelatría impresa del Parnaso áureo. Bulletin Hispanique, 109(2), 449-472.

Jiménez Montalvo, María del Mar. (2011). Una pequeña colección de chistes de Quevedo. Revista De Estudios Del Campo De Montiel, 2, 129-141.

Labougle, Eduardo (1924). José Antonio Miralla, poeta argentino precursor de la independencia de Cuba. Buenos Aires, Rosso.

Lehmann-Nitsche, Robert (1911). Adivinanzas rioplatenses. Buenos Aires, Coni hermanos.

López, C., \& Vicente, . (1999). El episodio de Polidoro en la Eneida (III 19-68): variantes mitográficas, paralelos folclóricos y muestras de su pervivencia literaria. Cuadernos De Filología Clásica. Estudios Latinos, 16, 27-44.

Mañero Lozano, David (dir./ed.) (2015-). Corpus de Literatura Oral. www.corpusdeliteraturaoral.es [CLO]

Mañero Lozano, David. (2016). Los retratos de la dama. Recursos de traslación y propagación literaria en la confluencia de la tradición culta y popular. Rivista Di Filologia e Letterature Ispaniche, 19, 9-41.

Mañero Lozano, David. (2020). La buenaventura del carnival. Tradición oral en un canto narrativo de transmisión moderna. Revista de Filología Española, 100(1), 141-160. https://doi.org/10.3989/rfe. 2020.006

Matos Moctezuma, Eduardo (1980). El negrito poeta mexicano. ¿Realidad o fantasía? México D. F., Porrúa.

Montiel López, Andrea (2016). Entre esqueletos y versos. El políptico de la muerte: un dispositivo de expiación de la Nueva España del siglo XVIII. Tesis de Maestría, Ciudad de México, UNAM.

Montes Arboleya, Luis Miguel. (2004). Historias mínimas. Bimenalia (blog). http://bimenalia.blogspot. com/2014/09/historias-minimas.html

Moreno-Mora, Manuel (1930). El Azuay literario. Cuenca [Ecuador], s. n. 
Muñoz Vernaza, Alberto (1903). Coincidencia? La Unión Literaria (Cuenca [Ecuador], s. n.) 3, 76-ss.

Navarro González, Alberto (1986). Una décima, atribuida a Miguel Hernández, sin autor conocido. Valle de Elda. Semanario de información local, deportes y espectáculos 1522, p. 3.

Nipho, Francisco Mariano, Cajón de sastre, o montón de muchas cosas, buenas, mejores y medianas; útiles, graciosas y modestas para ahuyentar el ocio, sin las rigideces del trabajo, antes bien a caricias del gusto. Madrid, Imprenta de D. Gabriel Ramírez, 1761 [Ejemplar de la Universidad de Oxford accesible en Internet: https://books.google.es/books?id=8qsGAAAAQAAJ\&printsec=front

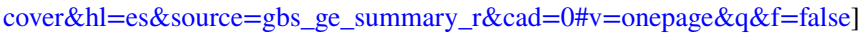

Olivares Figueroa, Rafael (1950). La adivinanza en la literatura y el folklore. Boletín De La Academia Venezolana, 18, 293-307.

Ortiz, Juan Francisco (1914). Reminiscencias de d. Juan Francisco Ortiz (1808-1861), con prólogo de don J. Manuel Marroquín. 2. ${ }^{a}$ ed., Bogotá, Librería americana.

Ortiz Rojas, José Joaquín (1880). Poesías de José Joaquín Ortiz. Bogotá, Echeverría hermanos.

Pedrosa, José Manuel (2003). Esopo, Dante, Giotto, Camões, Quevedo, Bocage, Pushkin... y Bajtin (o la metamorfosis del autor en personaje). Literary Research/Recherche littéraire 20, 39-40, 179-191.

Puig, Juan de la Cruz (1910). ed. Antología de poetas argentinos. Buenos Aires, Martín Biedma Editor.

Restrepo, Antonio José (1929). El cancionero de Antioquía de la tierra colombiana coleccionado y anotado por Antonio José Restrepo, con una introducción del mismo autor sobre la poesía popular. Lux.

Riquelme, Jesucristo. (1986). Apócrifos y hallazgos bibliográficos sobre Miguel Hernández (1919-1942). Canelobre, 6, 107-114.

Riquelme, Jesucristo (1990). El auto sacramental de Miguel Hernández. Propuesta de análisis del discurso teatral. Alicante, Técnica Gráfica Industrial.

Rodríguez Demorizi, Emilio (1938). Poesía popular dominicana. Santo Domingo, La Nación.

Saintyves, Pierre (1985). Las madres vírgenes y los embarazos milagrosos. Ensayo de mitología comparada (1908), trad. José Carlos Bermejo Barrera, Madrid, Akal Universitaria (serie interdisciplinar).

Sánchez Plazuelos, Miguel (1862). Cartas critico-poéticas. Madrid, Pascual Gracia y Orga.

Tello, Marco. (2004). El patrimonio lírico de Cuenca. Universidad de Cuenca.

Thompson, S. (1966). Motif-index of folk-literature; a classification of narrative in folktales, ballads, myths, fables, medieval romances, exemple, flabiaux, jest-books and local legends. Indiana University Press.

Valderrama, Adolfo (1866). Bosquejo histórico de la poesía chilena. Santiago, Imprenta chilena.

Varias, hermosas flores, del parnaso que en quatro floridos, uistosos quadros / plantaron iunto a su cristalina fuente D. Antonio Hurtado de Mendoza, D. Antonio de Solis, D. Francisco de la Torre y Sebil, D. Rodrigo Artes y Muñoz, Martin Iuan Barcelo, Iuan Bautista Aguilar, y otros se imprimieron en Valencia, en casa de Francisco Mestre, junto al Molino de Rovella, 1680 [Biblioteca Valenciana. Colección: BV Fondo antiguo. Ubicación: BV Carreres. Signatura: XVII/936. N. o de registro: 203]

Vela, Gregorio de Santiago. (1922). Ensayo de una biblioteca Ibero-Americana de la orden de San Agustín (Vol. 6). Provincia de Filipinas.

Vergara y Vergara, José María. (1931). Don José Antonio Miralla. La Caridad, 2, 14 (1865). Reimpr. en Obras escogidas. Bogotá, Editorial Minerva, III, 266-290.

Publisher's Note Springer Nature remains neutral with regard to jurisdictional claims in published maps and institutional affiliations. 